\title{
Interdisciplinaridade no Ensino Superior: de Imagem-objetivo à Realidade!
}

\author{
Interdisciplinary University Training: from \\ the Objective Image to Reality!
}

\author{
Maria Cristina Almeida de Souza $a^{I}$ \\ Elisete Casotti ${ }^{I}$ \\ Andréa Cristina de Farias Mello \\ Frederico dos Reis Goyatál \\ Therezinha Coelho de Souzal \\ Carlos Jesivan Marques Albuquerque
}

PALAVRAS-CHAVE:

- Aprendizagem;

- Ensino Superior;

- Curriculum.

\section{KEYWORDS:}

- Association Learning;

- Higher Education;

- Curriculum.

Recebido em: 13/09/2010

Aprovado em: 30/11/2010

REVISTA BRASILEIRA DE EDUCAÇ̄̃o MÉdICA

\section{ABSTRACT}

The authors report on their experience with the adoption of interdisciplinary activities in the teaching-learning process at the Dentistry School of Severino Sombra University (USS), promoted through the Pró-Saúde project. The study describes the stages in developing the proposal, the methodology, difficulties and resistance, and the results and spinoffs. The authors conclude that interdisciplinary activities can be applied to a higher education project as long as the teaching project has guidelines, a faculty body committed to the methodological innovation, and institutional policymakers dedicated

to implementing the changes.

\section{RESUMO}

Os autores relatam a experiência de adoção de ações interdisciplinares no processo de ensino-aprendizagem no curso de Odontologia da Universidade Severino Sombra (USS), as quais foram realizadas com fomento do Pró-Saúde. O objetivo do trabalho é descrever as etapas da construção da proposta, a metodologia adotada, as dificuldades e resistências enfrentadas, assim como os resultados e seus desdobramentos. A partir do relato é possível concluir que as ações interdisciplinares podem ser praticadas no ensino superior desde que haja uma diretriz no projeto pedagógico, uma equipe docente comprometida com a inovação metodológica e gestores institucionais empenhados em efetuar mudanças. 


\section{INTRODUÇÃO}

O velho sempre pode tornar-se novo, e em todo novo sempre existe algo de velho. Novo e velho são faces da mesma moeda-dependem da óptica de quem lê e da atitude disciplinar ou interdisciplinar de quem examina ${ }^{1}$.

Instituído em 1999, o curso de Odontologia da USS, em Vassouras/RJ, possuiu, até o ano de 2003, um Projeto Político Pedagógico (PPP) composto por uma tradicional matriz curricular, com disciplinas estruturadas a partir do paradigma cartesiano e, portanto, estanques, entre as quais inexistia a integração vertical ou horizontal. O desconhecimento, por parte do professor, do conteúdo programático das outras disciplinas que não aquelas por ele lecionadas ocasionou, entre outros aspectos, a repetição na oferta de determinados assuntos por vários docentes em distintos módulos de ensino.

Em 2004, com o apoio da Associação Brasileira de Ensino Odontológico/Seção Rio de Janeiro (Abeno/RJ) implantou-se no curso um PPP coletivamente construído, que, além de atender às Diretrizes Curriculares Nacionais para os cursos de graduação (DCNs), propôs a formação de um profissional crítico, reflexivo, atento aos múltiplos aspectos do processo saúde-doença da população e comprometido com os princípios do Sistema Único de Saúde (SUS).

Adotando o expresso por Silva², de que o currículo é relação social e, portanto, nunca é estático, mas ressignificado constantemente pelas relações sociais, tem-se que o ensino da saúde e os modos de produzir cuidado são também determinados e significados socialmente. Portanto, nesse processo, tomou-se o cuidado para que as mudanças não se limitassem a uma mera alteração de carga horária ou ao simples remanejamento de disciplinas, características dos projetos verticais que desconsideram o diálogo entre os atores envolvidos. A ideia era que se aprofundasse a discussão sobre a responsabilidade da formação do perfil do egresso.

Os módulos de ensino passaram, então, a ser oferecidos em núcleos temáticos, organizados por afinidade/inter-relação entre os diversos conteúdos programáticos - não mais fragmentados -, e constituíram três grandes núcleos: Pré-Clínico; Saúde e Sociedade; e Clínico. Este último, é conhecido como o "núcleo duro" do curso, pois historicamente tem-se mostrado mais refratário aos processos de mudanças. Em parte, a resistência às inovações no processo de ensino se deveu ao desconhecimento de como operacionalizá-las, à dificulda- de real de estabelecer relações horizontais com os demais especialistas nas práticas clínicas conjuntas e, ainda, ao receio da perda do prestígio pessoal ${ }^{3}$.

Para colocar em prática as ideias da nova matriz curricular, atendendo em última análise aos objetivos relativos ao perfil do egresso desejável, somaram-se à proposta curricular algumas atividades baseadas em metodologias inovadoras. Estas foram sendo implantadas gradativamente, potencializando áreas que desde o início participaram ativamente da mudança e agregando novos atores no decorrer do processo.

Aqui serão apresentadas três iniciativas: a inserção de temas transversais no processo formativo; a realização de seminários interdisciplinares para discussão de casos clínicos; e a proposição de prova única, interdisciplinar, no final do período, substituindo as de cada disciplina.

Todas as atividades aqui apresentadas foram sendo construídas e utilizadas com a seguinte intencionalidade: refletir sobre a importância do saber didático na atividade docente, compreendendo a interdisciplinaridade como elemento facilitador do processo de aprendizagem; criar estratégias locais e progressivas de integração de conteúdos; acumular experiências e vivências entre docentes de diferentes especialidades; proporcionar ao estudante espaços de construção de relações entre os conteúdos dos diferentes módulos e núcleos; desenvolver no aluno senso crítico, capacidade de argumentação, de expressão oral e redação; e rediscutir o processo de avaliação na prática docente.

O objetivo deste trabalho é, portanto, relatar o conjunto de iniciativas desenvolvidas no curso de Odontologia da USS, descrevendo as etapas da construção da proposta, a metodologia adotada, as resistências encontradas e o resultado advindo das mudanças curriculares.

\section{A inclusão de temas transversais e a interdisciplinaridade possível}

Uma das funções da Universidade é produzir conhecimentos e permitir, na medida de seu avanço, a compreensão ampla do ser humano e da vida em sociedade. Para Morin apud Fazenda ${ }^{1}$

devemos pensar o problema do ensino considerando, por um lado, os efeitos cada vez mais graves da compartimentação dos saberes e da incapacidade de articulá-los uns aos outros; por outro lado, considerando que a aptidão para contextualizar e integrar é uma qualidade fundamental humana, que precisa ser desenvolvida e não atrofiada. 
Na perspectiva de promover essa qualidade, iniciou-se uma experiência com a inclusão de temas transversais no decorrer do processo de formação. Entende-se aqui por temas transversais o conjunto de assuntos e conteúdos de natureza social, que não se configuram como disciplinas, têm características interdisciplinares e precisam ser tratados de forma transversal na matriz curricular (BRASIL, 1998). Esses temas objetivam a educação a partir de valores que tentam responder aos problemas sociais e conectar a escola com a vida das pessoas 5 .

Os temas foram selecionados a partir da atualidade e da presença do assunto na mídia; da relevância social e da proximidade com a realidade da formação em saúde; da potência do tema em ajudar a compreender a realidade; e do interesse dos alunos. Assuntos relacionados aos direitos humanos, à ética, à legalização do aborto e às políticas públicas, fome, desigualdades sociais, além de outros, foram selecionados e trabalhados.

Foi prevista, na forma de experiência piloto, uma carga horária semanal para o desenvolvimento dos temas elencados, que, inicialmente, envolveu docentes do núcleo Saúde e Sociedade. Isso garantiu um lugar de inclusão e evitou que a situação se torna-se algo como: "o que é de todos é de ninguém".

Nesse espaço, foi utilizado como material de suporte pedagógico vídeos, leitura de livros, notícias da imprensa escrita e televisiva e artigos científicos. As dinâmicas de aprendizado incluíram roteiros de pesquisa, entrevistas, convidados debatedores, júri simulado, seminários e, sistematicamente, a redação de textos argumentativos sobre os assuntos, desenvolvendo o senso crítico, a capacidade de argumentação, de expressão oral e a redação.

A participação de profissionais convidados, de áreas ligadas aos temas, enriqueceu as discussões e fortaleceu a interação entre os participantes. Os debates dos temas transversais realizaram-se dentro de uma perspectiva interdisciplinar e foram subsidiados pelo aprendizado que acadêmicos e docentes acumularam por meio de rodas de leitura e discussão de filmes. O debate contribuiu também para uma visão discente mais humanizada do usuário acolhido e atendido nas clínicas de ensino, incluindo a compreensão do contexto socioeconômico e cultural do paciente por ele atendido. Buscou-se destacar as relações interpessoais, com destaque para aquela que se estabelece entre o profissional e o paciente.

O processo foi auxiliado pelo incentivo do Pró-Saúde, que favoreceu a criação de um acervo de livros e filmes, bem como viabilizou a melhoria dos espaços multimídia ${ }^{6}$.
A autoavaliação, realizada pelos discentes, da metodologia adotada, revelou que eles reconhecem a função interdisciplinar da atividade, a importância do trabalho para uma melhor compreensão da realidade e também que adquiriram melhor capacitação para atuação como agentes transformadores da sociedade.

Por se acreditar que é função da Universidade oportunizar a construção de um conhecimento significativo para o estudante, destaca-se o que Moreno ${ }^{7}$ aponta como fundamental no processo de aprendizagem e que converge com metodologias que apostam na transversalidade e na interdisciplinaridade:

[...] o verdadeiro conhecimento é aquele que é utilizável, é fruto de uma elaboração (construção) pessoal, resultado de um processo interno de pensamento durante o qual o sujeito coordena diferentes noções entre si, atribuindo-lhes um significado, organizando-as, relacionando-as com outros anteriores. Este processo é inalienável e intransferível, ninguém pode realizá-lo por outra pessoa.

Contudo, a transversalidade representa uma prática pedagógica relativamente nova nos currículos de Odontologia e, para seu desenvolvimento, há necessidade de adoção de estratégias capazes de dar significado a essa prática.

Logo, entende-se que tanto a transversalidade como a interdisciplinaridade no ensino não são atributos espontâneos, especialmente contando com a herança da separação e da individualização das disciplinas, mas se crê que podem ser implementadas a partir de uma coordenação que identifique temas que pedem uma abordagem interdisciplinar e articule as disciplinas para que, com seus referenciais, possam contribuir na leitura da situação proposta.

A experiência que segue foi um desdobramento desse pensamento e também uma alternativa encontrada para envolver os docentes de outros núcleos, ampliando o número de professores envolvidos nos processos de mudança.

\section{Seminários interdisciplinares de estudo de casos}

Interdisciplinaridade não se ensina, nem se aprende: vive-se, exerce-se1.

A proposição de aproximar diferentes especialistas na discussão de casos clínicos parte do princípio de que as diferentes matérias devem fornecer instrumentos para que os alunos se aproximem da realidade a partir do ponto de vista de cada área, não descuidando de relacioná-lo e confrontá-lo com o ponto de vista de outras. 
Os seminários interdisciplinares de estudo de casos foram coordenados pelos docentes integrantes do núcleo Clínico em duas modalidades: casos elaborados por uma equipe de professores; e casos propostos por grupos de alunos sob supervisão de tutores - incluindo os do núcleo Saúde e Sociedade. Todos os casos, por orientação da equipe, continham informações sobre o contexto de vida do paciente, a condição bucal e sistêmica, esta última selecionada em função da prevalência e de sua ocorrência na clínica de ensino.

A apresentação dos casos se deu por meio de diferentes materiais de apoio, sendo que a preparação prévia da discussão do diagnóstico e do plano de tratamento envolveu a consulta a diferentes fontes. O principal objetivo foi romper barreiras disciplinares, estreitar a interface entre os módulos de ensino (por vezes de diferentes núcleos) e construir conhecimento a partir de uma abordagem multifacetada pelos referenciais de cada disciplina, mas complementares e necessários para dimensionar a complexidade de cada caso e propor condutas.

Os seminários se constituíram em um espaço importante para discutir as diferenças e as complementaridades de cada área, de promover trocas entre os especialistas e uma potente ferramenta na elaboração, revisão e pactuação de protocolos de atuação na clínica (condutas, terapêutica medicamentosa e outros).

Dentre as iniciativas do curso que buscaram integrar conteúdos e saberes, a adoção dessa estratégia mereceu destaque. Ao envolver docentes de distintas disciplinas e de diferentes núcleos, foi possível estabelecer uma prática de ensino em que todas as etapas que envolveram o manejo do caso clínico foram partilhadas: desde a problematização da situação, a identificação dos fatores relevantes (incluindo os determinantes sociais do processo saúde-doença), a proposição de diagnóstico, até a tomada de decisão sobre as condutas técnicas e recursos terapêuticos a serem utilizados.

Nesse processo, cada especialista percebeu as limitações do seu campo de estudos e compreendeu a dimensão e a necessidade da articulação de diferentes saberes. Observou-se que, isoladamente, nenhuma equipe docente realizaria a contento a atividade, que só foi possível em função da integração entre os professores.

A avaliação pelos alunos revelou que os seminários contribuíram tanto para a sua autonomia de aprendiz, como para a constituição de um pensar integrado para solucionar os problemas - recuperando, inclusive, conteúdos de disciplinas já cumpridas. Tais seminários ainda propiciaram aos alunos e professores a oportunidade de vivenciar, na prática universitária, o trabalho em grupo e otimizar o relacionamento intera- tivo entre os distintos atores envolvidos no processo. Assim, é possível admitir que tal experiência revela consonância com o que diz Fazenda (1), pois: “a atitude interdisciplinar não está na junção de conteúdos, nem na junção de métodos, muito menos na junção de disciplinas, nem na criação de novos conteúdos produtos dessas funções; a atitude interdisciplinar está contida nas pessoas que pensam o projeto educativo".

Na opinião dos professores, atores e autores fundamentais desse processo, a estratégia constituiu excelente exercício para romper o modelo cartesiano de organização do conhecimento, pois se apresenta como um desafio aos educadores, em sua maioria formados por instituições educacionais tradicionalistas e naturalmente reacionárias às mudanças.

Como a avaliação dos seminários foi positiva e na prática ocorreu uma aproximação e interlocução das disciplinas, nasceu a ideia de um projeto piloto de elaboração de uma única prova, elaborada de forma conjunta, substituindo aquelas por disciplina, e localizada na última avaliação semestral prevista.

\section{PROVA ÚNICA INTERDISCIPLINAR NO FINAL DO PERÍODO}

Diante do desafio e da dificuldade de elaboração, pela primeira vez, de uma avaliação interdisciplinar única, iniciou-se o processo de discussão por meio de oficinas conceituais sobre os temas avaliação e interdisciplinaridade. Essa atividade de suporte foi dividida em dois blocos: o primeiro envolveu todos os docentes do curso; e o segundo, com vários desdobramentos, trabalhou mais diretamente com um grupo de trabalho (GT) composto pelos professores do período ao qual a prova estava destinada.

O objetivo dessa atividade, no primeiro momento mediada por uma assessoria externa, foi iniciar a sensibilização para a responsabilidade do exercício docente e para as implicações que as opções pedagógicas de ensino e avaliação adotadas trazem para o perfil do egresso. A presença dos professores demonstrou comprometimento com as propostas de mudança e a compreensão da necessidade de realizá-las; docentes que raramente se encontravam tiveram a oportunidade de fazê-lo, e a troca de experiências, por vezes realizadas com o mesmo grupo de alunos para os quais estavam lecionando naquele período, foi maximizada.

O segundo bloco foi desenvolvido em grande parte pelo GT, contando pontualmente com o suporte da assessoria. Teve como objetivo, além da elaboração do instrumento, o amadurecimento de uma visão ampliada do processo de ensino e de avaliação para o período em questão. As reuniões do GT foram semanais e duraram, entre o primeiro encontro e a correção da prova, aproximadamente dois meses. 
Adotou-se, inicialmente, a proposta de um instrumento com 40 questões, no qual quatro seriam do tipo discursivas e de caráter interdisciplinar e as demais objetivas. Destas, duas estavam relacionadas aos temas transversais trabalhados no período e, para as demais, foi sugerido a busca de possíveis mas não obrigatórias - intersecções disciplinares.

A confecção do instrumento multi/interdisciplinar foi baseada em três etapas. A primeira, chamada global, referiu-se a um mapeamento da participação percentual de cada disciplina em termos de carga horária, observando o total de horas / aulas do período. Essa tarefa permitiu visualizar a distribuição das questões objetivas por disciplina, resguardando minimamente a inserção quantitativa de cada uma no período.

A segunda etapa, disciplinar, consistiu em um processo semelhante ao da fase anterior, só que referido aos conteúdos da ementa de cada disciplina. Exemplificando: cada disciplina elencou seus conteúdos e, de acordo com a contribuição em carga horária e a importância temática, definiu seu percentual no conjunto da ementa. Então, o número de questões por conteúdo seguiu esse raciocínio.

A terceira etapa, interdisciplinar, concentrou-se nas quatro questões discursivas e na identificação das possibilidades de interface das disciplinas do período. Ao final das discussões, cada questão articulou conhecimentos de pelo menos três áreas disciplinares, que foram contextualizados na forma de casos. Os professores dessas disciplinas elaboraram conjuntamente o suporte das questões e o padrão de resposta para cada uma. Ambos foram lidos para todos, e o conjunto do GT teceu críticas/sugestões sobre a extensão, natureza e relevância do suporte.

Alguns professores, convictos da excelência dos enunciados previamente preparados e das respostas esperadas, mostraram-se surpresos com as críticas (devidamente embasadas) emitidas pelos pares, as quais os levaram a reavaliar as questões e adotar uma nova postura, um novo olhar sobre a avaliação. Ao cabo da elaboração do instrumento, ele ainda foi avaliado pela equipe externa de assessoria e sofreu alguns ajustes de forma e conteúdo.

O aluno dispôs de quatro horas para realizar a prova; as respostas foram recolhidas em formulário de resposta, e o instrumento entregue ao estudante. Ao terminá-la, ele respondeu a um questionário por meio do qual avaliou itens, como: duração, contextualização, clareza das questões e outros, a partir do qual pôde fazer comentários/sugestões que contribuíssem para o aprimoramento do trabalho.

A correção da prova foi feita em conjunto pelo GT, com base no padrão de respostas já definido, e a nota da prova compôs parte percentual das notas de todas as disciplinas envolvidas.
Foi interessante constatar que as reuniões do GT funcionaram como verdadeiros conselhos de classe, nos quais informações individuais sobre os alunos foram trocadas, tais como: progresso/dificuldades no processo de ensino-aprendizagem; interesse; motivação; desempenho nas atividades práticas; tomada de atitude; relacionamento interpessoal; problemas pessoais, entre outros.

Claro ficou para a comunidade acadêmica que o ensino interdisciplinar surge da proposição de novos objetivos, de novos métodos, de uma nova forma de abordar os conteúdos e também de avaliar a aprendizagem, cuja tônica é a supressão do monólogo e a instauração de uma prática dialógica entre os sujeitos do processo de ensino-aprendizagem. Para tanto, fez-se necessária a eliminação das barreiras entre as disciplinas e também entre as pessoas que se propuseram a trabalhar de forma integrada1.

\section{CONCLUSÕES}

Os autores concluem que ações interdisciplinares são viáveis no ensino superior, desde que haja gestores institucionais compromissados em efetuar mudanças, que o Projeto Político Pedagógico contemple essa orientação e que, do ponto de vista operacional, conte com alguém que articule o coletivo nessa direção.

Uma equipe docente sensibilizada e comprometida com a inovação metodológica precisa ser preparada para enfrentar os desafios que o trabalho interdisciplinar impõe, sendo fortalecida conceitualmente e chamada a protagonizar diversas experiências que tenham convergência com as mudanças propostas - não se viabiliza um projeto mais amplo e consistente de inovações curriculares sem a diversificação de vivências e o envolvimento do maior número de pessoas possível.

Entretanto, as mudanças podem ser iniciadas com os professores menos reativos a adoção das inovações e, preferencialmente, formadores de opinião. A disposição para trabalhar interdisciplinarmente é um requisito indispensável ao professor comprometido com a necessária mudança no cotidiano acadêmico, no qual os módulos de ensino precisam integrar-se vertical e horizontalmente na matriz curricular, contribuindo para o desenvolvimento de competências e habilidades do futuro profissional que o mercado de trabalho demanda e que a Universidade se propõe a graduar.

Se os alunos tiverem oportunidades, dentro das universidades, que lhes permitam constituir um pensamento interdisciplinar, muito provavelmente eles sairão mais bem qualificados para atender às novas demandas da sociedade. A interdisciplinaridade não garantirá um ensino adequado ou um saber unificado, mas um ponto de vista que permitirá uma reflexão aprofundada e crítica sobre as metodologias educacionais. 


\section{REFERÊNCIAS}

1. Fazenda ICA. Interdisciplinaridade. Um projeto em parceria. 5. ed. Rio de Janeiro: Loyola, 2002.

2. Silva TT da. O currículo como fetiche. A poética e a política do texto curricular. Belo Horizonte: Autêntica, 2003.

3. Felippetto S. Espaços potenciais para o desenvolvimento da interdisciplinaridade no curso de odontologia. Dissertação (Mestrado). Universidade Vale do Itajaí, 2005.

4. Brasil. Parâmetros Curriculares Nacionais: $3^{\circ}$ e $4^{\circ}$ Ciclos do Ensino Fundamental: introdução aos Parâmetros Curriculares Nacionais. Secretaria de Educação Fundamental. Brasília, DF: MEC/SEF, 1998.

5. Araújo UF de. Temas transversais e a estratégia de projetos. São Paulo: Moderna, 2003.

6. Souza MCA, Silva MAM, Albuquerque CJM, Casotti E, Gouvêa MV. Filmes na sala de aula: estratégia para discussão de temas transversais no Curso de Odontologia da Universidade Severino Sombra - USS. Revista Fluminense de Odontologia. 2008;14(29):27-9.

7. Busquets MD. Temas transversais em educação: bases para uma formação integral. São Paulo: Ática, 2000.

\section{CONTRIBUIÇÃO DO AUTOR}

Maria Cristina Almeida de Souza contribuiu na redação final. Elisete Casotti, Andréa Cristina de Farias Mello redigiram o relato da experiência. Frederico dos Reis Goyatá Relaizou a revisão do texto. Therezinha Coelho de Souza realizou a pesquisa bibliográfica e deu assessoria pedagógica na redação. Carlos Jesivan Marques Albuquerque realizou a pesquisa bibliográfica

\section{CONFLITO DE INTERESSES}

Declarou não haver.

\section{ENDEREÇO PARA CORRESPONDÊNCIA}

Maria Cristina Almeida de Souza

Rua Aldo Cavalli, nº 169

Centro - Vassouras

CEP. 27700-970 RJ

E mail: mcas.souza@uol.com.br 